\title{
Quality Evaluation of Decoction Pieces of Gardeniae Fructus Based on Qualitative Analysis of the HPLC Fingerprint and Triple-Q-TOF-MS/MS Combined with Quantitative Analysis of 12 Representative Components
}

\author{
Jing Xu $\mathbb{D}^{1},{ }^{1}$ Rongrong Zhou $\mathbb{D}^{\mathbb{D}},{ }^{2}$ Lin Luo, ${ }^{1}$ Ying Dai $\mathbb{D},{ }^{3}$ Yaru Feng $\mathbb{D},{ }^{2}$ and Zhihua Dou $\mathbb{D}$, 2,3 \\ ${ }^{1}$ School of Pharmacy, Nantong University, Nantong 226019, Jiangsu, China \\ ${ }^{2}$ Nantong Third People's Hospital, Nantong University, Nantong 226006, Jiangsu, China \\ ${ }^{3}$ School of Pharmacy, Nanjing University of Chinese Medicine, Nanjing 210023, Jiangsu, China
}

Correspondence should be addressed to Yaru Feng; fengyaru21w@163.com and Zhihua Dou; zhihuadou@163.com

Received 1 September 2021; Accepted 14 December 2021; Published 26 February 2022

Academic Editor: Antony C. Calokerinos Copyright $\odot 2022$ Jing Xu et al. This is an open access article distributed under the Creative Commons Attribution License, which
permits unrestricted use, distribution, and reproduction in any medium, provided the original work is properly cited.

\begin{abstract}
In this study, quality evaluation (QE) of 40 batches of decoction pieces of Gardeniae Fructus (GF) produced by different manufacturers of herbal pieces was performed by qualitative analysis of the HPLC fingerprint and ultra-fast liquid chromatography (UFLC)-triple-Q-TOF-MS/MS combined with quantitative analysis of multiple components, which we established previously for QE of traditional medicine. First, HPLC fingerprints of 40 samples were determined, and the common peaks in the reference fingerprint were assigned. Second, the components of the common peaks in the HPLC fingerprints were identified by UFLC-triple-Q-TOF-MS/MS. Finally, the contents of the components confirmed by reference substances were measured. The results showed that there were 28 common peaks in the HPLC fingerprints of 40 samples. The components of these 28 common peaks were identified as 13 iridoids, 4 crocins, 7 monocyclic monoterpenoids, 3 organic acids, and 1 flavonoid. Of these, a total of 12 components, including 7 iridoids of geniposide, shanzhiside, geniposidic acid, deacetyl asperulosidic acid methyl ester, gardenoside, scandoside methyl ester, and genipin gentiobioside, 2 crocins such as crocin I and crocin II, 1 monocyclic monoterpenoid of jasminoside B, 1 organic acid of chlorogenic acid, and 1 flavonoid of rutin, were unambiguously identified by comparison with reference substances. There were certain differences in the contents of these 12 components among 40 samples. The geniposide content ranged from 37.917 to $72.216 \mathrm{mg} / \mathrm{g}$, and the total content of the 7 iridoids ranged from 59.931 to $94.314 \mathrm{mg} / \mathrm{g}$.
\end{abstract}

\section{Introduction}

Gardeniae Fructus (GF), the desiccative ripe fruit of Gardenia jasminoides Ellis (Rubiaceae), is a well-known and frequently used traditional medicine officially recorded in the Chinese and Japanese Pharmacopoeias [1-3]. To date, nearly 200 phytochemicals have been isolated and identified from GF [1, 4-9], which mainly include iridoids, crocins, monocyclic monoterpenoids, organic acids, and flavonoids $[1,10]$. The representative components of iridoids include geniposide, genipin gentiobioside, gardenoside, shanzhiside, deacetyl asperulosidic acid methyl ester (DAAEM), and scandoside methyl ester (SME) [11, 12], crocins include crocin I and crocin II [13], monocyclic monoterpenoids include jasminoside $\mathrm{A}$, jasminoside $\mathrm{B}$, and $6^{\prime}$-O-transsinapoyl jasminoside A [14], and organic acids and flavonoids including chlorogenic acid and rutin [15].

GF and its components exhibit a broad range of pharmacological activities, such as hepatoprotective and antiinflammatory [16, 17], renoprotective [8], antidiabetic and antioxidant [18, 19], antidepressant [20], antiviral [21], antithrombotic [22], and neuroprotective activities [23]. However, recent research results also show that high doses of GF and iridoids have certain hepatotoxicity and 
nephrotoxicity [24-26]. In other words, GF and iridoids have both toxic and protective effects on the liver and kidney. Therefore, strictly controlling the quality of GF is very important to ensure the safety and effectiveness of clinical medications.

The original medicinal materials of GF can only be used in the clinic after being processed into decoction pieces [27]. Decoction pieces of GF (Figure 1(a)) are the product of original medicinal materials of GF after removing impurities and crushing (Figure 1(b)) [2]. The quality of GF decoction pieces is directly related to the safety and effectiveness of clinical medication. At present, there are some literature reports on the quality evaluation $(\mathrm{QE})$ of original medicinal materials of GF [28-32], but there is no report on the QE of GF decoction pieces. Therefore, in this study, QE of 40 batches of GF decoction pieces produced by different manufacturers of herbal pieces was performed by qualitative analysis of the HPLC fingerprint and ultra-fast liquid chromatography (UFLC)-triple-Q-TOF-MS/MS combined with quantitative analysis of multiple components, which we established previously for QE of traditional medicine [33].

\section{Experimental}

2.1. Chemicals and Reagents. Reference substances geniposide (no. 110749-201718 with a purity of $\geq 97.6 \%$ (HPLC)), DAAME (no. 111786-201602 with a purity of $\geq 94.3 \%$ ), crocin I (no. 111588-201202 with a purity of $\geq 91.1 \%$ ), and crocin II (no. 111589-201103 with a purity of $\geq 91.9 \%$ ) were purchased from the National Institutes for Food and Drug Control (Beijing, China). Shanzhiside (no. CHB161228), geniposidic acid (no. CHB161101), gardenoside (no. CHB180124), SME (no. CHB160931), genipin gentiobioside (no. CHB160720), jasminoside B (no. CHB180326), chlorogenic acid (no. CHB170713), and rutin (no. CHB170303) were purchased from Chengdu Chroma Biotechnology Co., Ltd. (Chengdu, China) (all substances with a purity of $\geq 98 \%$ ). HPLC-grade methanol and LC/MS-grade acetonitrile were purchased from Fisher Scientific (Fair Lawn, NJ, USA). HPLC-grade formic acid and purified water were purchased from Nanjing Chemical Reagent Co., Ltd. (Nanjing, China) and Wahaha Group Co., Ltd. (Hangzhou, China), respectively.

2.2. Samples and Sample Preparation. Forty batches of GF decoction pieces produced by different manufacturers of herbal pieces were purchased from different large TCM hospitals in China; the information on all 40 samples is given in Table 1.

GF decoction pieces were ground into powders before use. Powder samples $(0.1 \mathrm{~g})$ were weighed accurately and placed in a $50 \mathrm{~mL}$ brown volumetric flask; approximately, $49 \mathrm{~mL}$ of $50 \%$ (v/v) methanol was added; the mixture was then extracted by ultrasonication $(200 \mathrm{~W}, 53 \mathrm{kHz})$ for $30 \mathrm{~min}$. After cooling to room temperature, $50 \%(\mathrm{v} / \mathrm{v})$ methanol was added for calibration of the volumetric flask and shaken well; the mixture was filtered through a $0.22 \mu \mathrm{m}$ filter membrane, and the filtrate was taken as a sample solution.
2.3. Preparation of Reference Substance Solutions. Twelve reference substance stock solutions with a concentration range of $0.1-4 \mathrm{mg} / \mathrm{mL}$ were prepared by accurately weighing appropriate amounts of 12 reference substances and dissolving them in $50 \%(\mathrm{v} / \mathrm{v})$ methanol.

Appropriate amounts of each reference substance stock solution were precisely measured, mixed together, and diluted with $50 \%(\mathrm{v} / \mathrm{v})$ methanol. Thus, the mixed reference substance solution for qualitative analysis in a concentration range of $1-67 \mu \mathrm{g} / \mathrm{mL}$ of each compound was prepared.

Working solution $\mathrm{A}$ in a concentration range of $3-381 \mu \mathrm{g} / \mathrm{mL}$ of each compound for quantitative analysis was prepared by the same method as that used in preparing the mixed reference substance solution for qualitative analysis. Working solutions B, C, and D were prepared by diluting working solution A with $50 \%$ methanol to 2,5 , and 10 times its initial volume, respectively.

2.4. Chromatographic Conditions for HPLC Fingerprint and Quantitative Analysis. Determination of the HPLC fingerprint and quantitative analysis of 12 components were performed on an HPLC system equipped with an e2695 separation unit, a 2998 PDA detector, and an Empower 3 data processing system (Waters Corp., Milford, MA, USA). Chromatographic separation was performed on a Symmetry $\mathrm{C}_{18}$ column $(4.6 \mathrm{~mm} \times 250 \mathrm{~mm}, 5 \mu \mathrm{m}$, Waters Corp., USA). The column was maintained at $30^{\circ} \mathrm{C}$. Acetonitrile $(\mathrm{A})$ and $0.1 \%(\mathrm{v} / \mathrm{v})$ formic acid (B) were used as mobile phases using the following gradient elution program: $0-5 \mathrm{~min}, 2 \% \mathrm{~A}$; 5-10 min, 2-5\% A; 10-45 min, 5-15\% A; 45-80 min, 15-40\% A; $80-82 \mathrm{~min}, 40-98 \%$ A. The injection volume of sample solution was $30 \mu \mathrm{L}$ at a flow rate of $1.0 \mathrm{~mL} / \mathrm{min}$. The wavelength for the determination of fingerprints and contents of the 7 iridoids, rutin, and jasminoside B was set at $254 \mathrm{~nm}$, and those for the determination of contents of chlorogenic acid and the 2 crocins were set at $324 \mathrm{~nm}$ and $430 \mathrm{~nm}$, respectively.

2.5. Validation of the HPLC Method for Fingerprint Analysis. By using peak 11 (genipin gentiobioside) as the reference peak and the relative standard deviation (RSD) value of the relative peak area (RPA) and the average relative retention time (RRT) of the 28 common peaks as measurement values, the HPLC method for fingerprint determination was validated with precision, stability, and repeatability tests. The precision was determined by six replicate injections of the same sample (S1) solution. The stability test was performed by injecting the sample solution (S1) at $0,6,12,18,24$, and $36 \mathrm{~h}$ after preparation. The repeatability was evaluated by six sample solutions prepared in parallel from S1.

2.6. Establishment and Similarity Analysis of the HPLC Fingerprint. The chromatographic data of 40 samples were imported into the Similarity Evaluation System for Chromatographic Fingerprint of Traditional Chinese Medicine software (Version 2012, Chinese Pharmacopoeia Commission, Beijing, China). The reference chromatogram was established using the chromatogram of sample 1 as the 


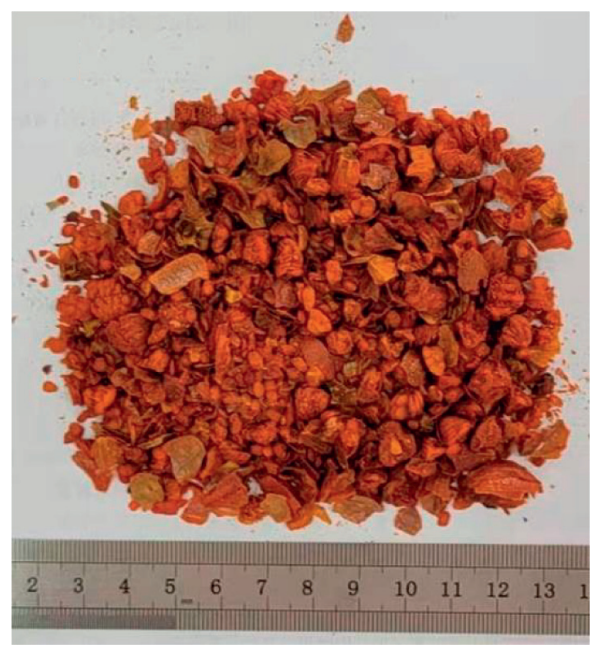

(a)

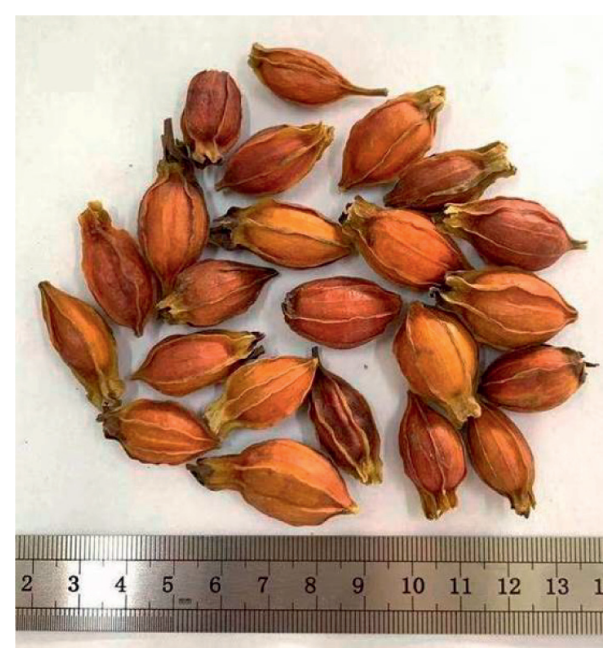

(b)

FIgURE 1: Decoction pieces of GF (a) and original medicinal materials of GF (b).

TABLE 1: Sample information and similarities.

\begin{tabular}{|c|c|c|c|c|}
\hline Sample no. & Manufacturers & Batch no. & Origins of herb & Similarity \\
\hline S1 & Nantong Sanyue Herbal Pieces Co., Ltd. & 171122 & Jiangxi & 0.999 \\
\hline S2 & Nantong Sanyue Herbal Pieces Co., Ltd. & 180402 & Jiangxi & 0.999 \\
\hline S3 & Nantong Sanyue Herbal Pieces Co., Ltd. & 200428 & Jiangxi & 0.993 \\
\hline S4 & Nantong Sanyue Herbal Pieces Co., Ltd. & 200616 & Jiangxi & 0.994 \\
\hline S5 & Nantong Sanyue Herbal Pieces Co., Ltd. & 200328 & Jiangxi & 0.994 \\
\hline S6 & Nantong Sanyue Herbal Pieces Co., Ltd. & 180131 & Jiangxi & 0.999 \\
\hline S7 & Nantong Sanyue Herbal Pieces Co., Ltd. & 180115 & Jiangxi & 0.996 \\
\hline S8 & Suzhou Tianling Herbal Pieces Co., Ltd. & 171222 & Jiangxi & 0.998 \\
\hline S9 & Suzhou Tianling Herbal Pieces Co., Ltd. & 171005010 & Jiangxi & 0.996 \\
\hline S10 & Suzhou Tianling Herbal Pieces Co., Ltd. & 151117010 & Jiangxi & 0.995 \\
\hline S11 & Suzhou Tianling Herbal Pieces Co., Ltd. & 16127010 & Jiangxi & 0.997 \\
\hline S12 & Bozhou Baishixin Herbal Pieces Co., Ltd. & 170601 & Jiangxi & 0.999 \\
\hline $\mathrm{S} 13$ & Bozhou Qiaocheng Wanshixiang Herbal Pieces Co., Ltd. & 180101 & Jiangxi & 0.995 \\
\hline S14 & Anhui Xiehecheng Pharmaceutical Herbal Pieces Co., Ltd. & 17110403 & Jiangxi & 0.999 \\
\hline $\mathrm{S} 15$ & Hebei Renxin Pharmaceutical Co., Ltd. & 22417008 & Jiangxi & 0.999 \\
\hline S16 & Anhui Meiyu Herbal Pieces Co., Ltd. & 111611027 & Jiangxi & 0.995 \\
\hline S17 & Jiangxi Jiangzhong Herbal Pieces Co., Ltd. & 171016 & Jiangxi & 0.998 \\
\hline S18 & Jiangxi Jiangzhong Herbal Pieces Co., Ltd. & 201222 & Jiangxi & 0.998 \\
\hline S19 & Jiangxi Zhangshu Tianqitang Herbal Pieces Co., Ltd. & 2010004 & Jiangxi & 0.989 \\
\hline S20 & Anhui Puren Herbal Pieces Co., Ltd. & 1709063 & Jiangxi & 0.998 \\
\hline S21 & Anhui Puren Herbal Pieces Co., Ltd. & 1711073 & Jiangxi & 0.997 \\
\hline S22 & Anhui Fengyuan Tongling Herbal Pieces Co., Ltd. & 15102002 & Jiangxi & 0.995 \\
\hline S23 & Shanghai Kangqiao Herbal Pieces Co., Ltd. & 180129 & Jiangxi & 0.998 \\
\hline S24 & Suzhou Boyuan Pharmaceutical Co., Ltd. & $150804-1$ & Jiangxi & 0.997 \\
\hline S25 & Anhui Huchuntang Herbal Pieces Co., Ltd. & 150911 & Jiangxi & 0.997 \\
\hline S26 & Bozhou Yonggang Herbal Pieces Co., Ltd. & 171021 & Jiangxi & 0.998 \\
\hline S27 & Bozhou Yonggang Herbal Pieces Co., Ltd. & 160111201 & Jiangxi & 0.998 \\
\hline $\mathrm{S} 28$ & Bozhou Yonggang Herbal Pieces Co., Ltd. & 210602 & Fujian & 0.995 \\
\hline S29 & Weiyuan Renze Pharmaceutical Co., Ltd. & 200809 & Fujian & 0.996 \\
\hline S30 & Fujian Mingyuan Pharmaceutical Co., Ltd. & 201001 & Fujian & 0.992 \\
\hline S31 & Jiangsu Longfengtang Herbal Pieces Co., Ltd. & 20022831 & Fujian & 0.995 \\
\hline S32 & Sichuan Tongshantang Herbal Pieces Co., Ltd. & 190801 & Sichuan & 0.990 \\
\hline S33 & Sichuan Zhongyong Pharmaceutical Co., Ltd. & 201201 & Sichuan & 0.981 \\
\hline S34 & Sichuan Gukang Pharmaceutical Co., Ltd. & 201201 & Sichuan & 0.997 \\
\hline S35 & Yancheng Herbal Pieces Co., Ltd. & 2018011502 & Hunan & 0.998 \\
\hline S36 & Hunan Nanguo Yaodu Herbal Pieces Co., Ltd. & 170801 & Hunan & 0.997 \\
\hline S37 & Nanning Shengyuan Herbal Pieces Co., Ltd. & 210201 & Guangxi & 0.994 \\
\hline S38 & Xuzhou Dapeng Herbal Pieces Co., Ltd. & 200309 & Guangxi & 0.996 \\
\hline S39 & Zhejiang Tongjuntang Herbal Pieces Co., Ltd. & 151115 & Zhejiang & 0.998 \\
\hline $\mathrm{S} 40$ & Tongling Hetian Herbal Pieces Co., Ltd. & 20170413 & Zhejiang & 0.997 \\
\hline
\end{tabular}


reference, and common peaks in this reference chromatogram were assigned. The similarities between sample chromatograms and reference chromatogram were calculated using the abovementioned software.

2.7. Mass Spectrometry Conditions for UFLC-Triple-Q-TOF$M S / M S$ Analysis. Identification of the components of common peaks in the HPLC fingerprint was performed on a UFLC-triple-Q-TOF-MS/MS system. Component separation was performed on a UFLC system (equipped with an LC-20AD XR quaternary pump, an SIL-20AC XR autosampler, and an SPD-M20A DAD detector, Shimadzu, Kyoto, Japan) by using the same column with the same mobile phases and gradient conditions as mentioned above. The injection volumes of both the mixed reference substance solution and sample solution were $20 \mu \mathrm{L}$. After component separation by UFLC, a Triple TOF 4600 system (AB SCIEX, Framingham, USA) was employed to acquire mass spectra in the negative ion mode with a DuoSpray source. The mass spectrometric parameters were set as follows: curtain gas (CUR) 35 psi, nebulizer gas (gas (1)) 65 psi, heater gas (gas (2)) $65 \mathrm{psi}$, ion spray voltage $4500 \mathrm{~V}$, and source temperature $550^{\circ} \mathrm{C}$. The TOFMS-IDA-10MS/MS method was used to obtain mass spectrometry data, and relevant parameters were set as follows: collision energy (CE) $-10 \mathrm{eV}$, decluster potential (DP) $-80 \mathrm{~V}$, accumulation time $250 \mathrm{~ms}$, mass range for TOF-MS detection $115-2000 \mathrm{Da}, \mathrm{CE}-35 \mathrm{eV}$, collision energy spread (CES) $15 \mathrm{eV}, \mathrm{DP}-80 \mathrm{~V}$, accumulation time $100 \mathrm{~ms}$, and mass range for the TOF-MS/MS detection 50-2000 Da. LC-MS/MS data were analyzed using PeakView mass spectrometry analysis software (Version 1.6, AB SCIEX, USA).

2.8. Method Validation of the Quantitative Analysis. The quantitative analysis method was validated by investigating the linear relationship, limit of detection (LOD), limit of quantitation (LOQ), precision, stability, repeatability, and recovery test of 12 components. The linear relationship was investigated by precisely injecting working solution $\mathrm{A}$ (10, $20,30$, and $40 \mu \mathrm{L})$ and working solutions $\mathrm{B}, \mathrm{C}$, and $\mathrm{D}(10 \mu \mathrm{L}$ of each solution) into the HPLC system to calculate the regression equation, correlation coefficient, and linear range for all 12 components. After diluted, working solution D was injected into the HPLC system many times; LOQ and LOD were determined on the basis of signal-to-noise ratios of 10 : 1 and $3: 1$, respectively. Intraday precision, interday precision, and stability were assessed by RSDs of the peak areas of the 12 components. The intraday precision was determined by six consecutive injections of $30 \mu \mathrm{L}$ working solution $\mathrm{A}$, and the interday precision was determined by six replicate injections of $30 \mu \mathrm{L}$ working solution $\mathrm{A}$, twice per day over 3 consecutive days. The stability test was carried out by using the peak areas of the 7 iridoids, rutin, and jasminoside B at $254 \mathrm{~nm}$, chlorogenic acid at $324 \mathrm{~nm}$, and 2 crocins at $430 \mathrm{~nm}$ detected in Section 2.5 of the stability test. By calculating the contents of 12 components according to the peak areas of the 7 iridoids, rutin, and jasminoside $B$ at $254 \mathrm{~nm}$, chlorogenic acid at $324 \mathrm{~nm}$, and 2 crocins at $430 \mathrm{~nm}$ detected in Section 2.5 of the repeatability test, and using the values of RSDs, the repeatability test was examined. For the recovery test, approximately $0.05 \mathrm{~g} \mathrm{S1}$ powder was precisely weighed, and 12 reference substance stock solutions were added at a sample/reference substance ratio of $1: 1$. Six sample solutions prepared in parallel by this method were analyzed, and the average recovery and RSDs of $12 \mathrm{com}$ ponents were calculated.

\section{Results and Discussion}

3.1. Validation of the Method for HPLC Fingerprint Analysis. The RSDs of RPA and RRT for precision were no more than $4.56 \%$ and $0.14 \%$, those for stability did not exceed $4.84 \%$ and $0.20 \%$, and those for repeatability were less than $4.87 \%$ and $0.21 \%$, respectively. The results met the fingerprinting quality standards for TCM injections [34].

3.2. Establishment and Similarity Analysis of the HPLC Fingerprint. As shown in Figure 2 and Table 1, 28 common peaks in the reference chromatogram were assigned. Similarities between the sample chromatograms and the reference chromatogram were all greater than 0.98 .

\subsection{Identification of the Common Peaks by Triple-Q-TOF-} $M S / M S$. A comparison between the negative ion mode and the positive ion mode revealed that the negative ion mode was much richer in information and thus was chosen for MS analysis. First, the total ion chromatograms of the sample and mixed reference substances (Figure 3) were extracted using PeakView software. Second, the mass spectral data and dissociative rules of the reference substances were summarized, and it was revealed that the quasimolecular ion [M$\mathrm{H}]^{-}$and/or $[\mathrm{M}+\mathrm{Cl}]^{-}$could be selected as the precursor ions to generate MS/MS product ion spectra. Finally, the retention time, quasimolecular ion, and MS/MS fragmentation patterns were compared between samples and reference substances or those reported in the literature. Online retrieval was performed in the database of PubChem (http:// pubchem.ncbi.nlm.nih. Gov); therefore, the components of the 28 common peaks in the HPLC fingerprint were identified (the mass spectral data are given in Table 2, and the structures or possible structures of the components of 28 common peaks are shown in Figure 4).

As given in Table 2 and Figure 4, the 28 identified components include 13 iridoids, 4 crocins, 7 monocyclic monoterpenoids, 3 organic acids, and 1 flavonoid, of which, 12 components were unambiguously identified by comparison with the reference substances, including 7 iridoids shanzhiside (peak 2), geniposidic acid (peak 3), DAAME (peak 4), gardenoside (peak 5), SME (peak 8), genipin gentiobioside (peak 11) and geniposide (peak 12), one monocyclic monoterpenoid jasminoside B (peak 9), one organic acid chlorogenic acid (peak 10), one flavonoid rutin (peak 15), and two crocins, crocin I (peak 20) and crocin II (peak 25). The mass spectrometry data of the components of peaks $1,6,7,13,14,17-19,21-24$, and 26-28 were the same as those reported in the previous literature. 


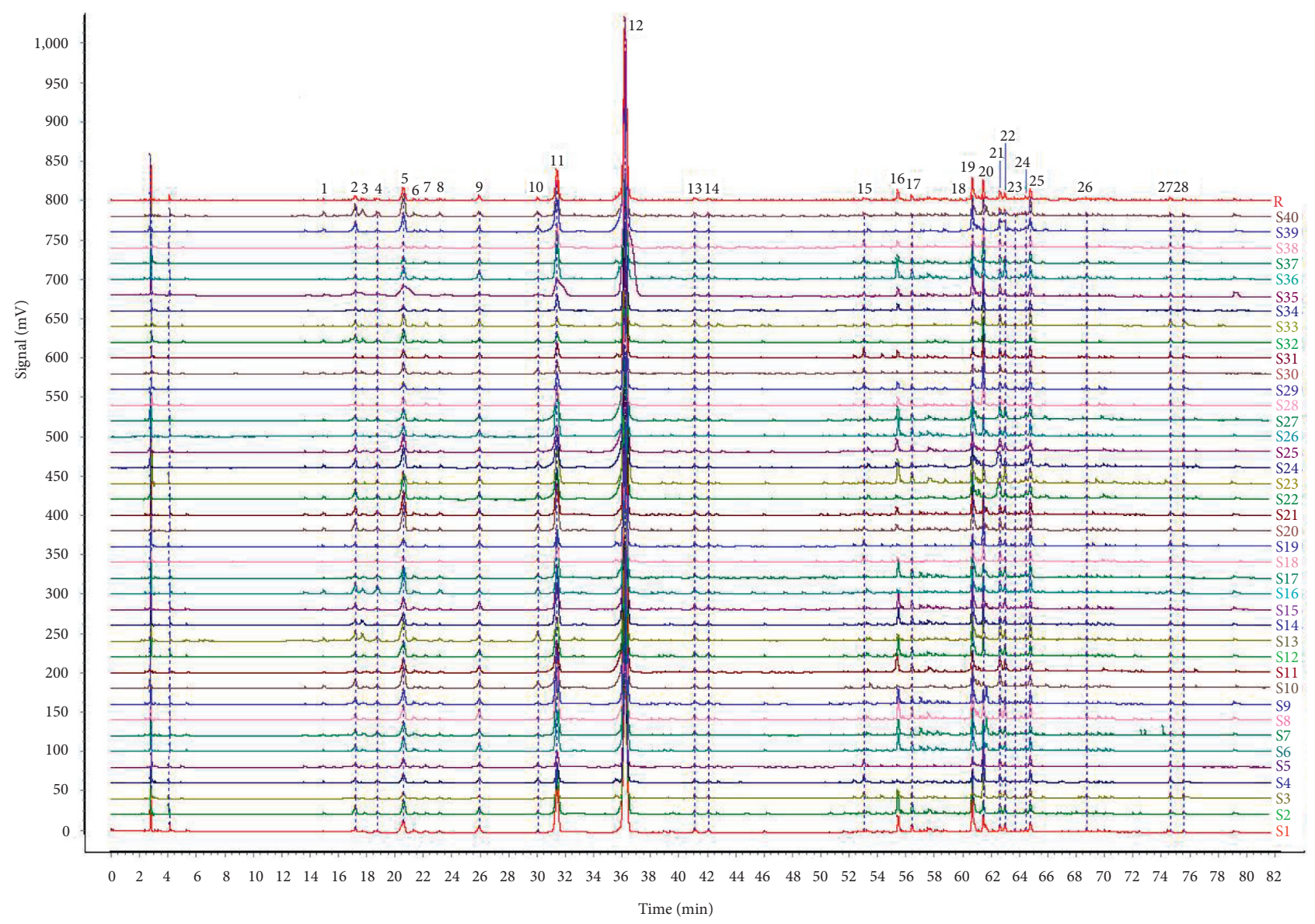

Figure 2: Chromatograms of 40 samples (S1-S40) and reference chromatogram (R).

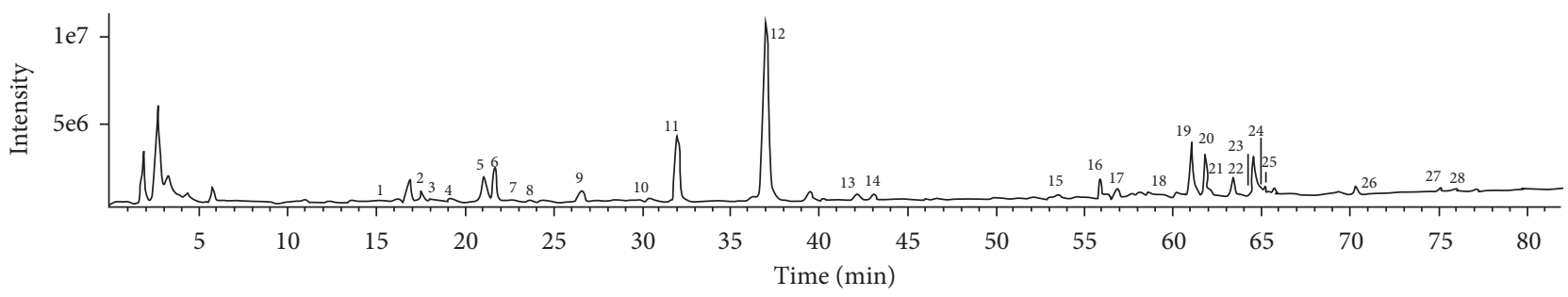

(a)

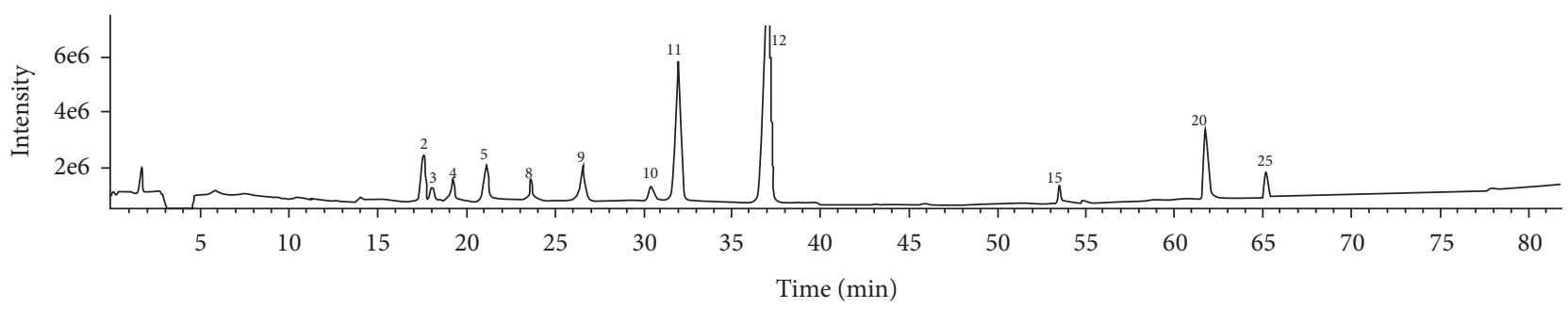

(b)

FIGURE 3: Total ion chromatograms of samples (a) and mixed reference substances (b).

For peak 16, its quasimolecular ion was at a $\mathrm{m} / z$ of $597.1855\left([\mathrm{M}-\mathrm{H}]^{-}\right)$and a $\mathrm{m} / z$ of $633.1619\left([\mathrm{M}+\mathrm{Cl}]^{-}\right)$, which was in accordance with the formula $\mathrm{C}_{27} \mathrm{H}_{34} \mathrm{O}_{15}$ based on its accurate mass. $\mathrm{Li}$ et al. also detected a component with the molecular formula $\mathrm{C}_{27} \mathrm{H}_{34} \mathrm{O}_{15}$ in GF by Q-TOF-MS and speculated that this component was penta-acetyl geniposide [10]. However, penta-acetyl geniposide is an artificial acetylated product from geniposide, which does not exist 


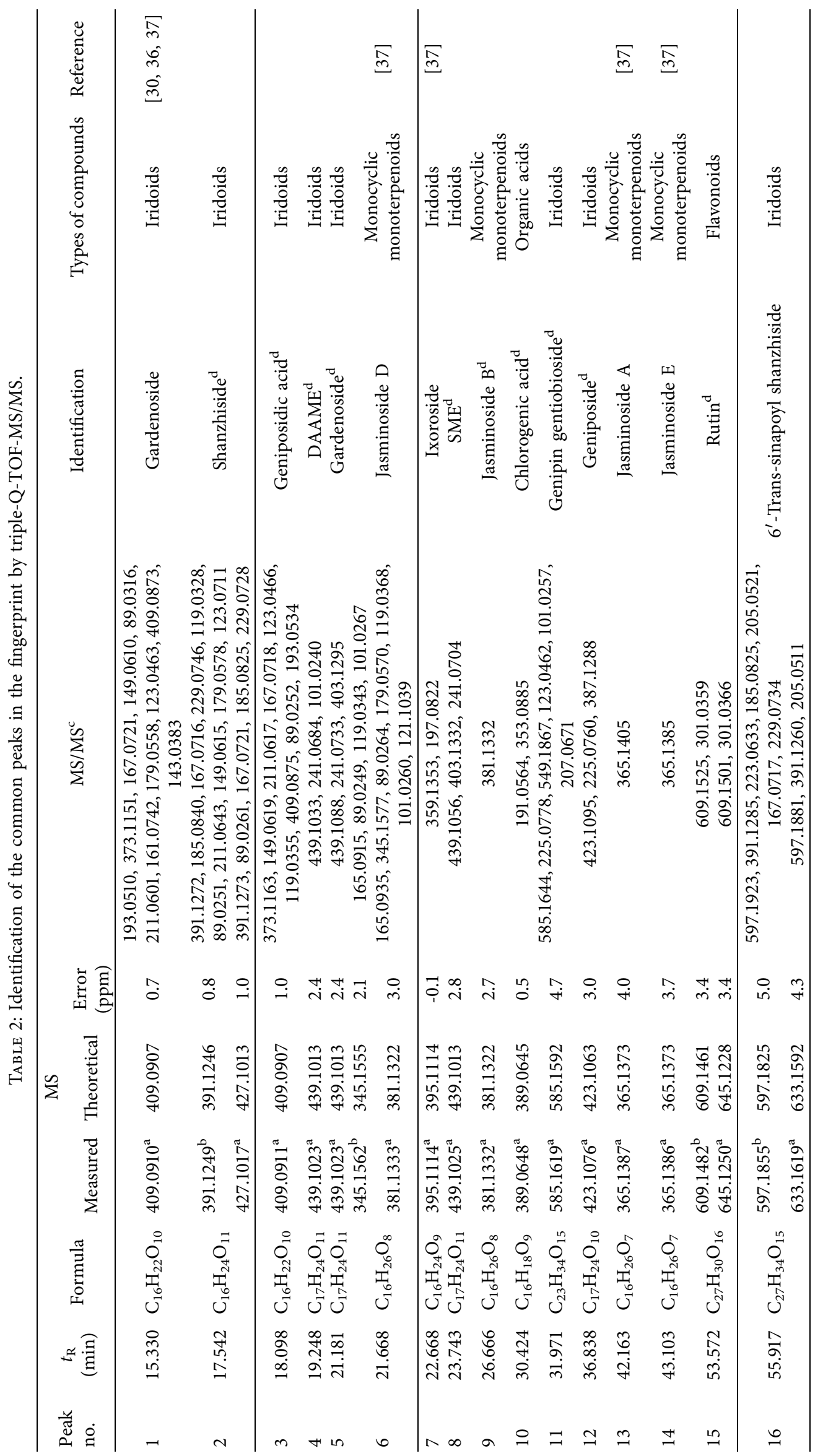




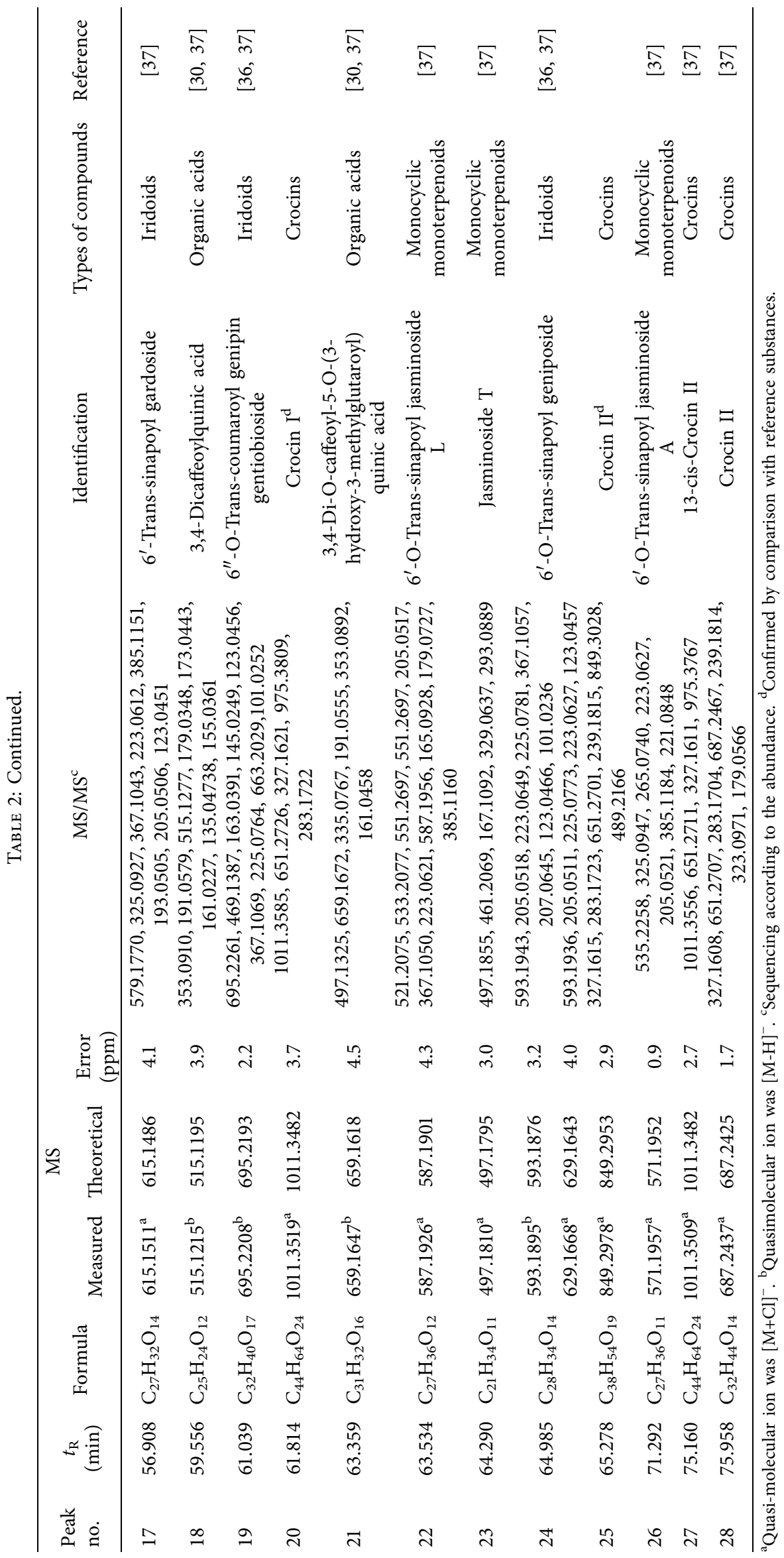




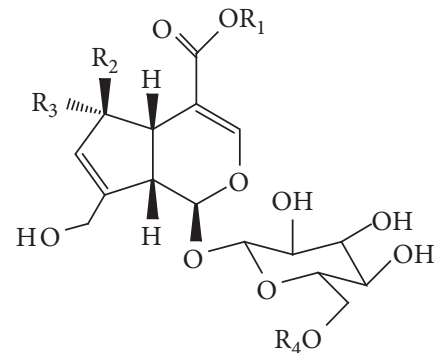

$\begin{array}{ccccc}\text { Peak No. } & \mathrm{R}_{1} & \mathrm{R}_{2} & \mathrm{R}_{3} & \mathrm{R}_{4} \\ 3 & \mathrm{H} & \mathrm{H} & \mathrm{H} & \mathrm{H} \\ 4 & \mathrm{CH}_{3} & \mathrm{H} & \mathrm{OH} & \mathrm{H} \\ 8 & \mathrm{CH}_{3} & \mathrm{OH} & \mathrm{H} & \mathrm{H} \\ 11 & \mathrm{CH}_{3} & \mathrm{H} & \mathrm{H} & \text { glc } \\ 12 & \mathrm{CH}_{3} & \mathrm{H} & \mathrm{H} & \mathrm{H} \\ 19 & \mathrm{CH}_{3} & \mathrm{H} & \mathrm{H} & \text { glc-cou } \\ 24 & \mathrm{CH}_{3} & \mathrm{H} & \mathrm{H} & \text { sin }\end{array}$

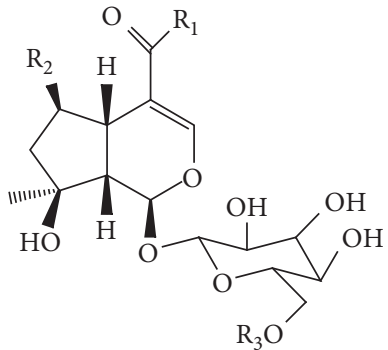

Peak No. $\mathrm{R}_{1} \quad \mathrm{R}_{2} \quad \mathrm{R}_{3}$

$\begin{array}{llll}2 & \mathrm{OH} & \mathrm{OH} & \mathrm{H}\end{array}$

$\begin{array}{llll}7 & \mathrm{H} & \mathrm{H} & \mathrm{H}\end{array}$

$16 \mathrm{OH} \mathrm{OH}$ sin
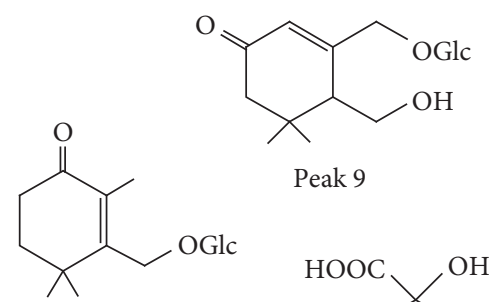<smiles>[R]OC(=O)/C(C)=C/C=C/C(C)=C/C</smiles>

Peak 14

Peak No. $R_{1} \quad R_{2}$

27 gentibi gentibi

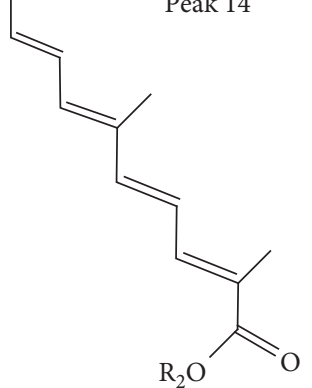

乐

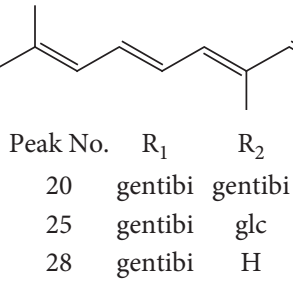<smiles>C[C@@H]1OC[C@@H](OC(=O)/C=C/c2ccccc2)[C@H](O)[C@H](O)[C@H]1O</smiles>
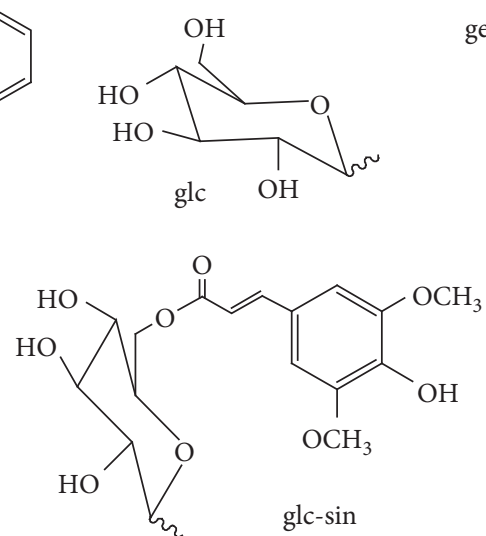<smiles>COc1cc(/C=C/C(C)=O)cc(OC)c1O</smiles>

Peak 9
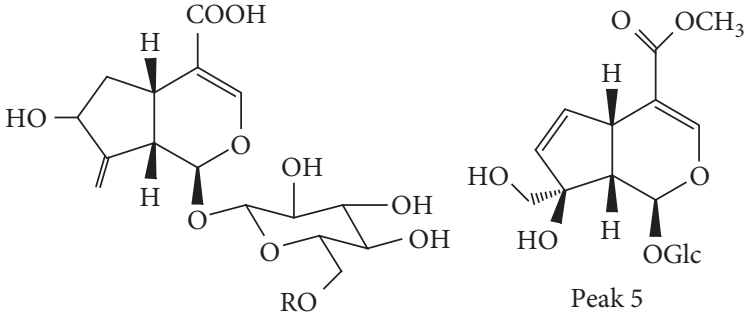

Peak No. $\quad \mathrm{R}$

$1 \mathrm{H}$

$17 \sin$<smiles>[R10]C1=C(C)C([R17])C([R])CC1(C)C</smiles><smiles>CC1=CC(=O)CC(C)(C)C1CO</smiles>

Peak No. R

13 glc

23 glc-api

Peak No. $\mathrm{R}_{1} \quad \mathrm{R}_{2} \quad \mathrm{R}_{3}$

$6 \mathrm{CHO}$ glc $\mathrm{OH}$

HOOC ${ }^{\mathrm{OH}}$

$22 \mathrm{COOH}$ glc-sin $\mathrm{H}$

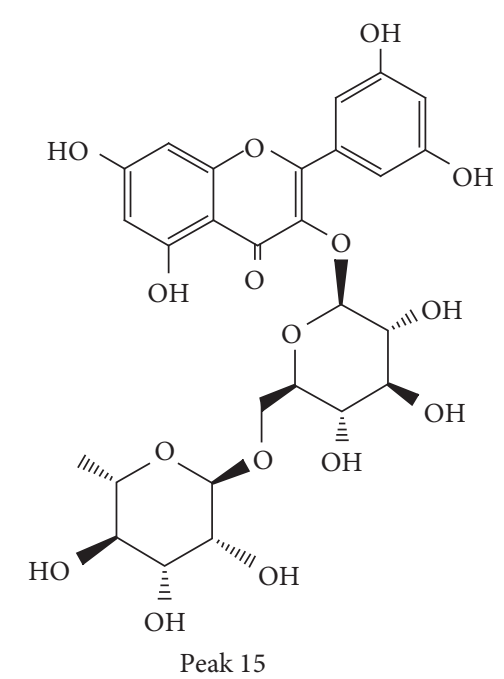

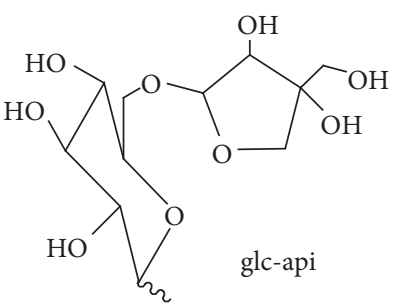<smiles>CC(=O)CC(C)(O)CC(=O)O</smiles><smiles>O=C(/C=C/c1ccc(O)cc1)OC1COC(O)C(O)C1O</smiles>

Figure 4: Structures or possible structures of the components of 28 common peaks. 
TABLE 3: Results of the investigation of the linear relationship, LOD, and LOQ.

\begin{tabular}{|c|c|c|c|c|c|}
\hline Reference substance & Regression equation & $R^{2}$ & Linear range/ng & $\mathrm{LOD} / \mathrm{ng}$ & $\mathrm{LOQ} / \mathrm{ng}$ \\
\hline Shanzhiside & $Y=410245 X-1479$ & 0.9998 & $25.78-1030$ & 2.06 & 7.73 \\
\hline Geniposidic acid & $Y=664663 \mathrm{X}-107$ & 0.9997 & $6-240$ & 1.8 & 5.3 \\
\hline DAAME & $Y=604893 \mathrm{X}-2756$ & 0.9999 & $8.806-352.24$ & 1.76 & 7.04 \\
\hline Gardenoside & $Y=505562 X-3934$ & 0.9999 & $16.848-673.92$ & 1.68 & 6.74 \\
\hline SME & $Y=615010 X-1709$ & 1.0000 & $7.196-287.84$ & 2.16 & 7.2 \\
\hline Jasminoside B & $Y=989612 X-7323$ & 0.9995 & $12.1-484$ & 2.42 & 6.05 \\
\hline Chlorogenic acid & $Y=2746452 X-3099$ & 0.9999 & $3.0768-123.072$ & 0.92 & 3.69 \\
\hline Genipin gentiobioside & $Y=460657 \mathrm{X}-29122$ & 0.9999 & $187.75-7510$ & 3.76 & 13.14 \\
\hline Geniposide & $Y=746351 X-82879$ & 0.9999 & $380.6-15224$ & 2.44 & 12.18 \\
\hline Rutin & $Y=1071542 X-3095$ & 0.9998 & $6.57-262.6$ & 1.97 & 5.91 \\
\hline Crocin I & $Y=4453568 X-29472$ & 0.9999 & $20.25-810$ & 0.61 & 2.03 \\
\hline Crocin II & $Y=4595808 \mathrm{X}-23116$ & 0.9999 & $15-600$ & 0.45 & 1.5 \\
\hline
\end{tabular}

TABLE 4: Results of precision, stability, repeatability, and recovery tests $(n=6)$.

\begin{tabular}{|c|c|c|c|c|c|c|}
\hline \multirow{2}{*}{ Components } & \multicolumn{2}{|c|}{ Precision RSD (\%) } & \multirow{2}{*}{ Stability RSD (\%) } & \multirow{2}{*}{ Repeatability RSD (\%) } & \multicolumn{2}{|c|}{ Recovery } \\
\hline & Intraday & Interday & & & Mean (\%) & RSD (\%) \\
\hline Shanzhiside & 0.87 & 0.98 & 4.96 & 0.97 & 96.58 & 1.80 \\
\hline Geniposidic acid & 1.06 & 1.15 & 4.82 & 3.92 & 100.10 & 3.23 \\
\hline DAAME & 0.80 & 0.91 & 3.63 & 1.35 & 98.11 & 2.86 \\
\hline Gardenoside & 0.76 & 0.86 & 1.23 & 1.01 & 97.73 & 3.36 \\
\hline SME & 0.85 & 0.95 & 4.84 & 2.05 & 98.17 & 1.89 \\
\hline Jasminoside B & 1.25 & 1.37 & 2.26 & 2.07 & 98.46 & 2.74 \\
\hline Chlorogenic acid & 1.16 & 1.07 & 3.54 & 2.88 & 102.65 & 3.61 \\
\hline Genipin gentiobioside & 0.65 & 0.76 & 1.59 & 1.37 & 99.85 & 3.06 \\
\hline Geniposide & 0.63 & 0.73 & 1.51 & 1.61 & 101.18 & 1.85 \\
\hline Rutin & 0.50 & 0.59 & 4.69 & 2.85 & 96.37 & 4.30 \\
\hline Crocin I & 0.48 & 0.56 & 1.33 & 2.57 & 99.05 & 3.76 \\
\hline Crocin II & 0.49 & 0.56 & 1.36 & 2.20 & 96.51 & 3.59 \\
\hline
\end{tabular}

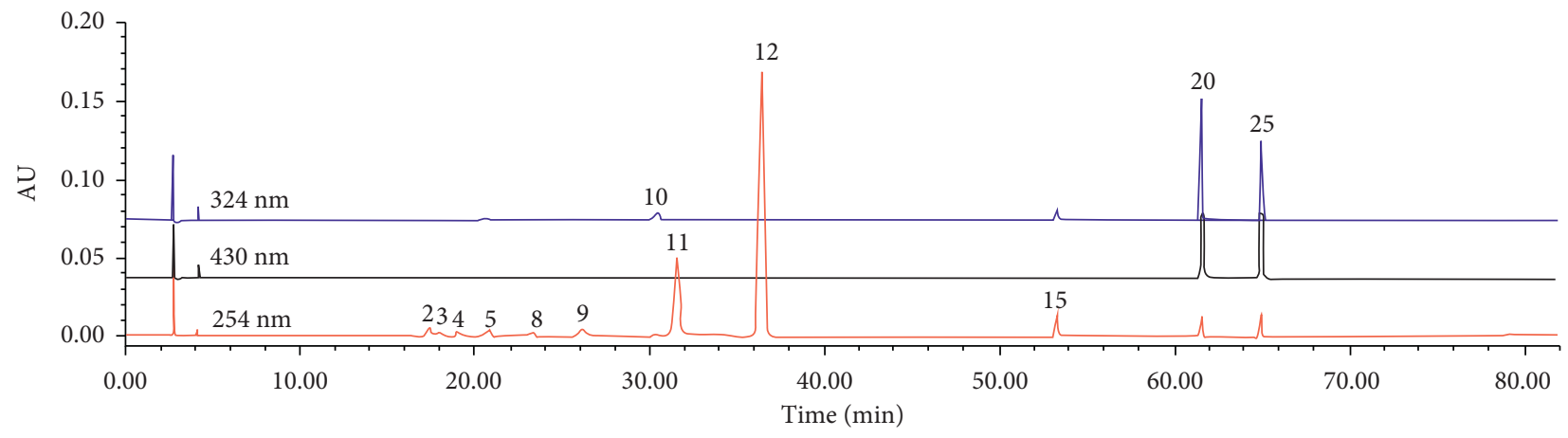

(a)

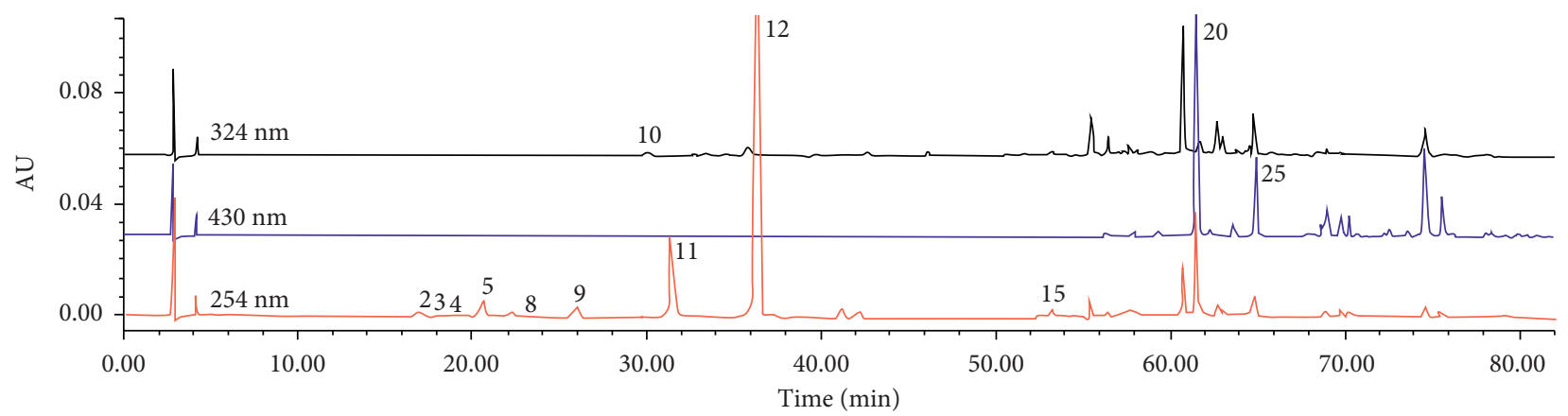

(b)

FIGURE 5: HPLC chromatograms of the mixed reference substances (a) and sample (b). The number of peaks is the same as in Table 2. 


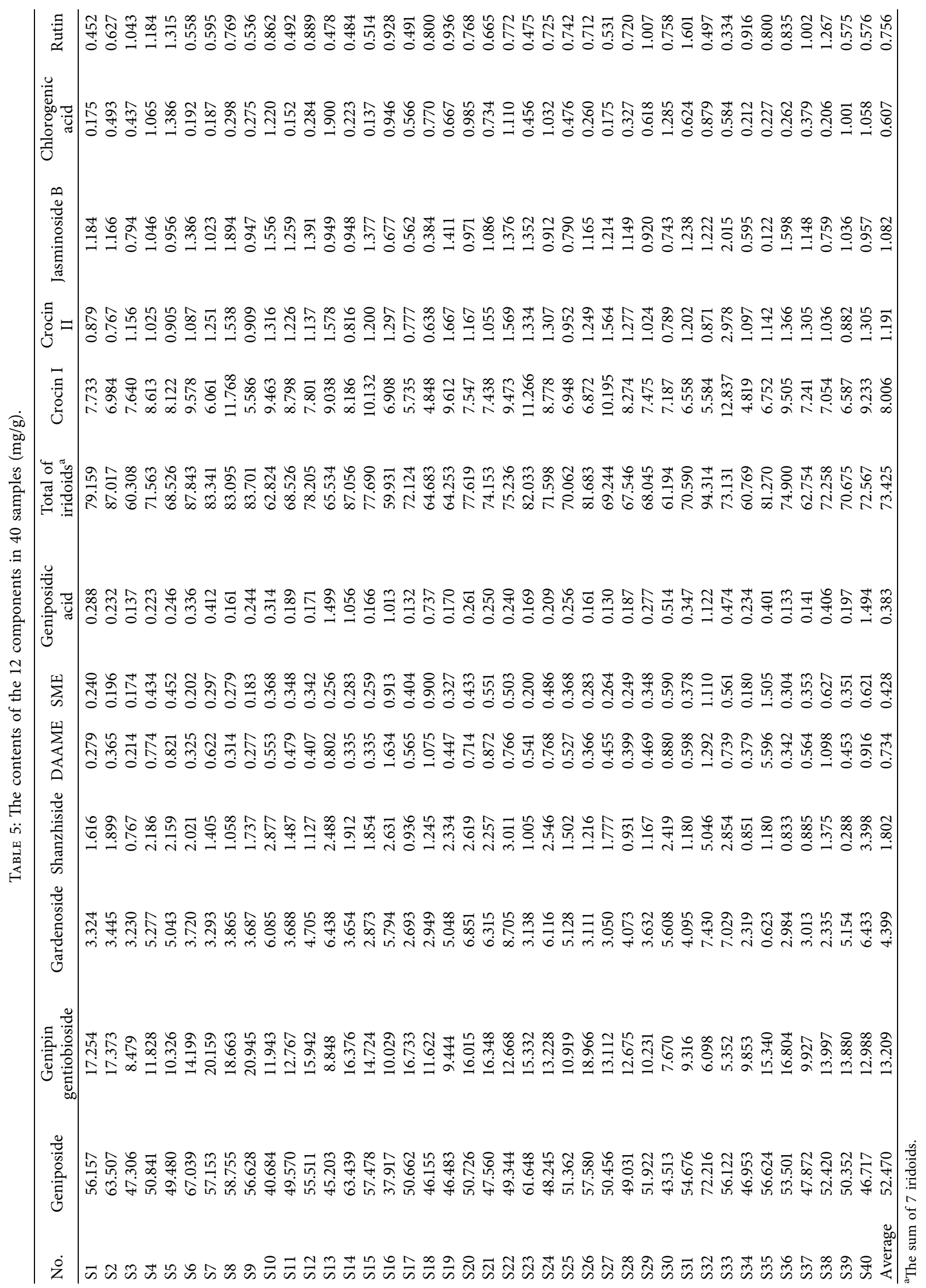


naturally in GF [35]. The [M-H $]^{-}$ion of peak 16 was selected as the precursor ion to generate MS/MS spectra, and fragment ions at $\mathrm{m} / z$ 597.1923, 391.1285, 229.0734, 223.0633, $205.0521,185.0825$, and 167.0717 were obtained. The ions at $\mathrm{m} / z 223.0633\left(\mathrm{C}_{11} \mathrm{H}_{11} \mathrm{O}_{5}{ }^{-}\right)$and $205.0521\left(\mathrm{C}_{11} \mathrm{H}_{9} \mathrm{O}_{4}{ }^{-}\right)$could be assigned as [sinapoyl-H] ${ }^{-}$and [sinapoyl- $\left.\mathrm{H}_{-} \mathrm{H}_{2} \mathrm{O}\right]^{-}$, suggesting the presence of a sinapoyl group in the molecule [36]. The ions at $\mathrm{m} / z 597.1923\left(\mathrm{C}_{27} \mathrm{H}_{33} \mathrm{O}_{15}{ }^{-}\right)$corresponding to [M-H] $]^{-}$loss of a sinapoyl residue $\left(\mathrm{C}_{11} \mathrm{H}_{10} \mathrm{O}_{4}{ }^{-}\right)$yielded a predominant fragment ion at $\mathrm{m} / z 391.1285\left(\mathrm{C}_{16} \mathrm{H}_{23} \mathrm{O}_{11}{ }^{-}\right)$, which was consistent with the precursor ion of shanzhiside. Fragment ions at $\mathrm{m} / z 229.0734\left(\mathrm{C}_{10} \mathrm{H}_{13} \mathrm{O}_{6}{ }^{-}\right), 185.0825$ $\left(\mathrm{C}_{9} \mathrm{H}_{13} \mathrm{O}_{4}{ }^{-}\right)$, and $167.0717\left(\mathrm{C}_{9} \mathrm{H}_{11} \mathrm{O}_{3}{ }^{-}\right)$were produced by the ions at $\mathrm{m} / z 391.1285$ with successive loss of a glucose unit $\left(\mathrm{C}_{6} \mathrm{H}_{10} \mathrm{O}_{5}^{-}\right), \mathrm{CO}_{2}$, and $\mathrm{H}_{2} \mathrm{O}$, respectively, which exhibited the same fragmentation pathway as shanzhiside. The abovementioned fragmentation pathways basically confirmed that the basic skeleton of the component of peak $\mathbf{1 6}$ was shanzhiside. Therefore, peak 16 was identified as a component of shanzhiside substituted by sinapoyl at $6^{\prime}-\mathrm{O}$, and a natural compound with this kind of structure was also found in the compound database PubChem. Referring to the names of the components of peaks 17 and 24, the component of peak 16 was temporarily named as $6^{\prime}$-transsinapoyl shanzhiside. To the best of our knowledge, this component was first detected in GF [1, 4-9].

3.4. Validation of Method for Quantitative Analysis. As given in Tables 3 and 4, the coefficient of determination values $R^{2}$ was greater than 0.9995 , all RSDs of the intraday precision, interday precision, stability, and repeatability were less than $5 \%$, the average recovery rates were $96.37-102.65 \%$, and the RSDs were $1.80-4.30 \%$. The above results met the requirements of the standard drug quality analysis method in the Chinese Pharmacopoeia [38].

3.5. Wavelength Selection for Quantitative Analysis of 12 Components. All 12 components could be detected at $254 \mathrm{~nm}$, but the absorption of chlorogenic acid (peak 10) was stronger at $324 \mathrm{~nm}$, and the absorptions of crocin I (peak 20) and crocin II (peak 25) were stronger at approximately $430 \mathrm{~nm}$. Therefore, a wavelength of $324 \mathrm{~nm}$ was selected for the detection of chlorogenic acid, and a wavelength of $430 \mathrm{~nm}$ was selected for the detection of crocin I and crocin II. The chromatograms of the mixed reference substances and sample are shown in Figure 5.

3.6. Contents of 12 Representative Components in 40 Samples. As given in Table 5, there were certain differences in the contents of the 12 representative components among 40 samples, of which, the content of geniposide ranged from 37.917 to $72.216 \mathrm{mg} / \mathrm{g}$, and the total content of the 7 iridoids ranged from 59.931 to $94.314 \mathrm{mg} / \mathrm{g}$. Iridoids, especially geniposide, have both toxic and protective effects on the liver and kidney $[16,24-26,39,40]$. It has been reported that the intragastric administration of $50 \mathrm{mg} / \mathrm{kg} / \mathrm{d}$ bodyweight (human equivalent dose of $8 \mathrm{mg} / \mathrm{kg} / \mathrm{d}$ bodyweight) geniposide in rats for 12 weeks can lead to liver and kidney damage [24]. According to this report, adults weighing $60 \mathrm{~kg}$ may suffer liver and kidney damage if they take $6 \mathrm{~g}$ or $10 \mathrm{~g}$ GF decoction pieces with a content of $80 \mathrm{mg} / \mathrm{g}$ or $48 \mathrm{mg} / \mathrm{g}$ every day for a long time. The recommended clinical dose of GF decoction pieces is $6-10 \mathrm{~g} / \mathrm{d}$ in the Chinese Pharmacopoeia [2]. Table 5 provides that the geniposide content in most batches of GF decoction pieces exceeded $48 \mathrm{mg} / \mathrm{g}$. Therefore, the content of representative components such as geniposide in GF decoction pieces should be measured before clinical use, and the dose of GF decoction pieces should be adjusted according to the content of these components to achieve a therapeutic effect and avoid adverse reactions.

\section{Conclusion}

In this study, QE of 40 batches of decoction pieces of GF produced by different manufacturers of herbal pieces is performed by qualitative analysis of the HPLC fingerprint and UFLC-triple-Q-TOF-MS/MS combined with quantitative analysis of multiple components, which we established previously for QE of traditional medicine. The results show that there are 28 common peaks in the HPLC fingerprints of 40 samples. The similarities between the sample chromatograms and reference chromatogram were higher. The components of these 28 common peaks are identified as 13 iridoids, 4 crocins, 7 monocyclic monoterpenoids, 3 organic acids, and 1 flavonoid. Of these, a total of 12 components, including the seven iridoids geniposide, shanzhiside, geniposidic acid, DAAMS, gardenoside, SME, and genipin gentiobioside, crocin I and crocin II, the monocyclic monoterpenoid jasminoside $\mathrm{B}$, and the organic acid chlorogenic acid and the flavonoid rutin, were unambiguously identified by comparison with reference substances. There were certain differences in the contents of these 12 components among 40 samples; the geniposide content ranged from 37.917 to $67.039 \mathrm{mg} / \mathrm{g}$, the total content of the 7 iridoids ranged from 37.917 to $67.039 \mathrm{mg} / \mathrm{g}$, and the total content of 7 iridoids ranged from 59.931 to $87.843 \mathrm{mg} / \mathrm{g}$. The content of representative components, such as geniposide, in GF decoction pieces should be measured before clinical use, and the dose of GF decoction pieces should be adjusted according to the content of these components to achieve a therapeutic effect and avoid adverse reactions.

\section{Data Availability}

The data used to support the findings of this study are included within the article.

\section{Conflicts of Interest}

The authors declare that they have no conflicts of interest. 


\section{Authors' Contributions}

Jing $\mathrm{Xu}$ and Rongrong Zhou contributed equally to this work.

\section{Acknowledgments}

This study was supported by Key Research and Development (Social Development) Fund Project of Jiangsu Province, China (BE2018674), and Traditional Chinese Medicine Science and Technology Plan Project of Jiangsu Province, China (YB201836)

\section{References}

[1] L. P. Chen and M. X. Li, "Gardenia jasminoides ellis: ethnopharmacology, phytochemistry, and pharmacological and industrial applications of an important traditional Chinese medicine," Journal of Ethnopharmacology, vol. 257, 2020.

[2] Chinese Pharmacopoeia Commission, Chinese Pharmacopoeia, pp. 259-260, China Medical Science Press, Beijing, China, 2020.

[3] Editorial Board of Japanese Pharmaceutical Bureau, Japanese Pharmacopoeia (XVII), p. 1854, Japanese Ministry of Health Press, Tokyo, Japan, 2016.

[4] P. H. Shu, M. Z. Yu, and H. Q. Zhu, "Two new iridoid glycosides from Gardeniae Fructus," Carbohydrate Research, vol. 501, 2021.

[5] Y. G. Cao, Y. J. Ren, and Y. L. Liu, "Iridoid glycosides and lignans from the fruits of Gardenia jasminoides Eills," Phytochemistry, vol. 190, 2021.

[6] X. Chen, Y. G. Cao, and Y. J. Ren, "A new quinic acid derivative with $\alpha$-glucosidase inhibitory activity from the fruit of Gardenia jasminoides," Natural Product Research, vol. 35, no. 1-7, 2021.

[7] H. B. Li, J. F. Ma, and Y. D. Mei, "Two new iridoid glycosides from the fruit of Gardenia jasminoides," Natural Product Research, vol. 36, no. 1, pp. 186-192, 2022.

[8] Y.-G. Cao, Y.-L. Zhang, M.-N. Zeng et al., "Renoprotective mono- and triterpenoids from the fruit of gardenia jasminoides," Journal of Natural Products, vol. 83, no. 4, pp. 1118-1130, 2020.

[9] D. Lu, W. Zhang, Y. Jiang et al., "Two new triterpenoids from Gardenia jasminoides fruits," Natural Product Research, vol. 33, no. 19, pp. 2789-2794, 2019.

[10] W. Li, C. Ren, C. Fei et al., "Analysis of the chemical composition changes of Gardeniae Fructus before and after processing based on ultra-high-performance liquid chromatography quadrupole time-of-flight mass spectrometry," Journal of Separation Science, vol. 44, no. 5, pp. 981-991, 2021.

[11] T. Zhou, W. Zhao, G. Fan, Y Chai, and Y Wu, "Isolation and purification of iridoid glycosides from Gardenia jasminoides Ellis by isocratic reversed-phase two-dimensional preparative high-performance liquid chromatography with column switch technology," Journal of chromatography. B, Analytical technologies in the biomedical and life sciences, vol. 858, no. 1-2, pp. 296-301, 2007.

[12] Y. Wang, Y. Chen, L. Deng et al., "Systematic separation and purification of iridoid glycosides and crocetin derivatives from Gardenia jasminoides Ellis by high-speed countercurrent chromatography," Phytochemical Analysis, vol. 26, no. 3, pp. 202-208, 2015.
[13] Y. N. Song, Y. Wang, and Y. H. Zheng, "Crocins: a comprehensive review of structural characteristics, pharmacokinetics and therapeutic effects," Fitoterapia, vol. 153, 2021.

[14] Q. C. Chen, U. Youn, B. S. Min, and K. Bae, "Pyronane monoterpenoids from the fruit of gardenia jasminoides," Journal of Natural Products, vol. 71, no. 16, pp. 995-999, 2008.

[15] E. Ouyang, X. Li, and C. Zhang, "Simultaneous determination of geniposide, chlorogenic acid, crocin1, and rutin in crude and processed Fructus Gardeniae extracts by high performance liquid chromatography," Pharmacognosy Magazine, vol. 7, no. 28, pp. 267-270, 2011.

[16] R. Dong, Q. Tian, Y. Shi et al., “An integrated strategy for rapid discovery and identification of quality markers in gardenia fructus using an omics discrimination-grey correlation-biological verification method," Frontiers in Pharmacology, vol. 12, Article ID 705498, 2021.

[17] P. Chen, Y. Chen, Y. Wang et al., "Comparative evaluation of hepatoprotective activities of geniposide, crocins and crocetin by CCl4-induced liver injury in mice," Biomolecules \& Therapeutics, vol. 24, no. 2, pp. 156-162, 2016.

[18] K. Saravanakumar, S. J. Park, and A. Sathiyaseelan, "Metabolite profiling of methanolic extract of gardenia jaminoides by LCMS/MS and GC-MS and its anti-diabetic, and anti-oxidant activities," Pharmaceuticals, vol. 14, no. 2, 2021.

[19] L. Wang, C. Yang, F. Song, Z Liu, and S Liu, “Therapeutic effectiveness of gardenia jasminoides on type 2 diabetic rats: mass spectrometry-based metabolomics approach," Journal of Agricultural and Food Chemistry, vol. 68, no. 36, pp. 96739682, 2020.

[20] B. M. Xia, X. Y. Huang, G. D. Sun, and W. W. Tao, "Iridoids from Gardeniae fructus ameliorates depression by enhancing synaptic plasticity via AMPA receptor-mTOR signaling," Journal of Ethnopharmacology, vol. 268, 2021.

[21] S. Guo, L. Bao, C. Li, J Sun, R Zhao, and X Cui, "Antiviral activity of iridoid glycosides extracted from Fructus Gardeniae against influenza A virus by PACT-dependent suppression of viral RNA replication,” Scientific Reports, vol. 10, no. 1, p. 1897, 2020.

[22] Y. P. Shi, Y. G. Zhang, and H. N. Li, "Discovery and identification of antithrombotic chemical markers in Gardenia Fructus by herbal metabolomics and zebrafish model," Journal of Ethnopharmacology, vol. 253, 2020.

[23] Y. Ni, L. Li, and W. Y. Zhang, "Discovery and LC-MS characterization of new crocins in gardeniae fructus and their neuroprotective potential," Journal of Agricultural and Food Chemistry, vol. 65, no. 14, pp. 2936-2946, 2020.

[24] C. N. Li, X. Gao, and X. C. Gao, "Effects of medicine food Fructus Gardeniae on liver and kidney functions after oral administration to rats for 12 weeks," Journal of Food Biochemistry, vol. 45, no. 7, 2021.

[25] C. Li, M. Lan, J. Lv et al., "Screening of the hepatotoxic components in fructus gardeniae and their effects on rat liver BRL-3A cells," Molecules, vol. 24, no. 21, 2019.

[26] J. Tian, Y. Yi, Y. Zhao et al., "Oral chronic toxicity study of geniposide in rats," Journal of Ethnopharmacology, vol. 213, pp. 166-175, 2018.

[27] H. Liu, Y.-F. Chen, F. Li, and H.-Y. Zhang, "Fructus Gardenia (Gardenia jasminoides J. Ellis) phytochemistry, pharmacology of cardiovascular, and safety with the perspective of new drugs development," Journal of Asian Natural Products Research, vol. 15, no. 1, pp. 94-110, 2013.

[28] F. Yin, X. Wu, L. Li et al., "Quality control of gardeniae fructus by HPLC-PDA fingerprint coupled with chemometric methods," Journal of Chromatographic Science, vol. 53, no. 10, pp. 1685-1694, 2015. 
[29] X. Wu, Y. Zhou, F. Yin et al., "Quality control and producing areas differentiation of Gardeniae Fructus for eight bioactive constituents by HPLC-DAD-ESI/MS," Phytomedicine, vol. 21, no. 4, pp. 551-559, 2014.

[30] Y. Han, J. Wen, T. Zhou, and G. Fan, "Chemical fingerprinting of Gardenia jasminoides Ellis by HPLC-DAD-ESIMS combined with chemometrics methods," Food Chemistry, vol. 188, pp. 648-657, 2015.

[31] S. A. Coran, S. Mulas, and A. Vasconi, "Profiling of components and validated determination of iridoids in gardenia jasminoides ellis fruit by a high-performance-thin-layerchromatography/mass spectrometry approach," Journal of Chromatography A, vol. 1325, pp. 221-226, 2014.

[32] E. J. Lee, J. K. Hong, and W. K. Whang, "Simultaneous determination of bioactive marker compounds from gardeniae fructus by high performance liquid chromatography," Archives of Pharmacal Research, vol. 37, no. 8, pp. 992-1000, 2014.

[33] Y. Dai, Z. H. Dou, and R. R. Zhou, "Quality evaluation of Artemisia capillaris Thunb. based on qualitative analysis of the HPLC fingerprint and UFLC-Q-TOF-MS/MS combined with quantitative analysis of multi-components," Journal of Analytical Methods in Chemistry, vol. 2021, 2021.

[34] SFDA (State Food and Drug Administration of China), Technical Requirements for the Development of Fingerprints of TCM Injections, SFDA (State Food and Drug Administration of China), China, 2000.

[35] C. Peng, C. Huang, and C. Wang, "The anti-tumor effect and mechanisms of action of penta-acetyl geniposide," Current Cancer Drug Targets, vol. 5, no. 4, pp. 299-305, 2005.

[36] Z. Fu, R. Xue, Z. Li et al., "Fragmentation patterns study of iridoid glycosides in Fructus Gardeniae by HPLC-Q/TOF-MS/MS," Biomedical Chromatography, vol. 28, no. 12, pp. 1795-1807, 2014.

[37] L. Wang, S. Liu, X. Zhang, J. Xing, Z. Liu, and F. Song, "A strategy for identification and structural characterization of compounds from gardenia jasminoides by integrating macroporous resin column chromatography and liquid chromatography-tandem mass spectrometry combined with ion-mobility spectrometry," Journal of Chromatography A, vol. 1452, pp. 47-57, 2016.

[38] China Medical Science Press, Pharmacopoeia of China, Part 4, China Medical Science Press, Beijing, China, 2020.

[39] F. Li, Y. Chen, Y. Li, M Huang, and W Zhao, "Geniposide alleviates diabetic nephropathy of mice through AMPK/ SIRT1/NF- $\kappa$ B pathway," European Journal of Pharmacology, vol. 886, p. 173449, 2020.

[40] E. Mahgoub, S. M. Kumaraswamy, K. H. Kader et al., "Genipin attenuates cisplatin-induced nephrotoxicity by counteracting oxidative stress, inflammation, and apoptosis," Biomedicine \& Pharmacotherapy, vol. 93, pp. 1083-1097, 2017. 